\title{
Game Analysis of Knowledge Transfer of Product Innovation Team in Multinational Corporations
}

\author{
Luo Ling, Wang Juan-ru
}

School of Management, Northwestern Polytechnical University, Xi'an, China

Email address:

rowlinghn@163.com (Luo Ling), wjuanru@nwpu.edu.cn (Wang Juan-ru)

\section{To cite this article:}

Luo Ling, Wang Juan-ru. Game Analysis of Knowledge Transfer of Product Innovation Team in Multinational Corporations. Journal of Human Resource Management. Vol. 5, No. 4, 2017, pp. 63-69. doi: 10.11648/j.jhrm.20170504.12

Received: August 29, 2017; Accepted: September 9, 2017; Published: September 29, 2017

\begin{abstract}
Product innovation team is a knowledge-intensive organization, which can integrate the dominant resources effectively in order to creative competive advantage for multinational corporations. Knowledge sharing is the key to success for product innovation team. This paper proposes a game theoric model that can indicate team members' collaboration on a product innovation through knowledge sharing. In addition, knowledge-sharing activities in three types of product innovation team are analyzed. The proposed model indentifies conditions that lead to collaboration among team members in the product innovation team, which maximizes product performance. The insights obtained from the model and possible implications in product innovation team are discussed.
\end{abstract}

Keywords: Knowledge Sharing, Product Innovation Team, Game Theory, Incentive Mechanism

\section{Introduction}

Innovations form the lifelines of organizations [1]. Especially, innovative new products and speed to market are often regarded as keys to survival and success in today's highly competitive, turbulent market environment [2]. However, product innovations have become increasingly complex, costly, and risky due to changing customer preferences, extensive competitive pressure, and rapid and radical technological changes [1]. New product innovation is a knowledge-intensive and cross-functional activity [3]. Knowledge is believed to be the most important input factor in product innovations. As such, knowledge development has been a major strategic goal for firms in their innovation effort [4].

According to the extent of usefulness of knowledge, the knowledge that each employee might hold can be categorized as either being complementary knowledge or supplementary knowledge. Complementary knowledge is more likely to lead to radical product development efforts but also to higher performance in the long term. However, supplementary knowledge serves different need as the form broadens the scope of the present invention and provides valuable insights for other potentially unrelated projects [5]. That is to say, new product innovations are often depended on the knowledge, especially the complementary knowledge. However, knowledge is a unique, inimitable, and valuable resources for firms, and it dispersed in different units and embedded in different individuals [1]. It is often difficult for companies to develop new products unless they capture, transfer, and disseminate different type knowledge through inter-discipline cooperation. Knowledge exchange and transfer has been considered an effective and efficient way of successful innovation. Thus, knowledge exchange and sharing are often prerequisites to innovation performance.

Most authors claim that team building is crucial for start-ups success, by bringing together complementary competencies and knowledge. The team members usually have diverse backgrounds and experiences that can generate novel and potentially useful ideas [6, 7]. Increasingly organizations are using product innovation team's knowledge transfer activities to improve their new product development performance. Product innovation team is a group which is composed of individuals coming from different countries or units who cooperate with each other in order to achieve a certain new product development goal. In order to develop new products successfully, there is growing need for companies to coordinate and integrate the dispersed knowledge through building a product innovation team.

However, knowledge sharing and exchanges do not occur in 
isolation. There is the potential for "free riders" members who enjoy the benefits of the collective good without contributing to its establishment and/or maintenance. "Free-riding" in the knowledge sharing team is a known phenomenon that usually results in selfish behavior. When exerting effort without monitoring or negotiating, each team member may stop exerting effort and enjoy the fruits of others' work [8]. Therefore, effectively knowledge sharing and exchanges is the vital to the success of product innovation team. How to improve the enthusiasm of the team members' knowledge sharing, and to avoid the emergence of members "free rider" problem in the team cooperation are the keys to solve the problem of team knowledge transfer and share.

Many authors have done some researches about team members' knowledge sharing. Various approaches have been applied to understand this issue.

Dyer and Nobeoka [9] indicated the free rider problems and undesirable spillovers problems are two key dilemmas in knowledge sharing, and it is important to empirically examine how Toyota has attempted to solve the dilemmas associated with knowledge sharing (e.g., free rider problems). The results show that creating "rules" or norms for participation in the network which essentially eliminates the free rider problem and creating incentives for knowledge acquisition and application are effective to knowledge sharing.

$\mathrm{Ba}$ et al. [10] contend that to deal with such a free-rider problem in knowledge sharing there has to be proper incentive-aligned mechanism that induces people to reveal their true valuation of knowledge.

$\mathrm{Ba}$ et al. [11] note that Knowledge sharing is both constrained and difficult without proper and necessary incentives for doing so. Economic and monetary incentives should be explored in a knowledge-sharing context where, for example, people may be willing to give away certain knowledge when they perceive value in return for having done so.

Bartol and Srivastava [12] suggest that rewards are important for most mechanisms of knowledge sharing. However, the rewards will not achieve their intended results unless basic guidelines for the effective use of rewards, such as clear goals, rewords of value and sufficient employee self-efficacy are also followed.

Without appropriate incentive programs, most knowledge management projects would not achieve their stated goals and objectives [8].

Ho et al. [13] believe that rewards are necessary for the individuals to share, since knowledge sharing significantly contributing to a firm's competitive advantage may diminish the individual's competitiveness.

Given the importance of knowledge sharing, scholars and practitioners would be interested in identifying tools that enhance knowledge sharing within the organization. Knowledge sharing is defined as individuals sharing organizationally relevant information, ideas, suggestions, and expertise with one another [12].

Ardichvili [14] indicates that, when employees view knowledge as a public good belonging to the whole organization, knowledge flows easily. However, even when individuals give the highest priority to the interests of the organization and of their community, they tend to shy away from contributing knowledge for a variety of reasons. Specifically, employees hesitate to contribute out of fear of criticism, or of misleading the community members (not being sure that their contributions are important, or completely accurate, or relevant to a specific discussion). Developing various types of trust, ranging from the knowledge-based and the institution-based trust, can remove the identified barriers.

Shih et al. [15] indicated that knowledge sharing plays an important role in a high-tech company's performance and innovation. In implementing knowledge sharing, high-tech firms often encounter setbacks due to neglecting human nature and the knowledge trading mechanism within organizations. They propose a holistic knowledge sharing framework by applying game theory, co-opetition, agent contest and reward systems, to solve the employee's dilemma and free-rider behavior problems. Based on this framework, they categorize high-tech firms into four types of knowledge sharing, such as job guarantee, individual performance, team performance, and team learning. Empirical results showed that the type of team learning firm with agent contest and reward systems designed for both team and individual could build a co-opetitive knowledge sharing environment.

Bandyopadhyay and Pathak [16] model the interaction between employees of the "host" firm and the outsourcing firm, who have to share their knowledge and skill sets in order to work effectively as a team, but might be naturally antagonistic towards each other. The analysis shows that when the degree of complementarity of knowledge between the employees is high enough, better payoffs can be achieved if the top management enforces cooperation between the employees. In these situations, the involvement of the top management extends far beyond negotiating the contract to make the outsourcing successful.

Knowledge in organizations needs to be treated as a public good if it is to be available to everyone in the organization. But any public good is faced with the free-rider problem eventually leading to individuals undercontributing to the public good (thereby sharing less than required knowledge) [16].

Samieh and Wahba [17] study the role of individual's attitude towards knowledge sharing, from a socio-psychological perspective, and how it drives the decision to share knowledge. They propose that an individual's knowledge sharing behavior is driven by a set of salient beliefs that are not unlike the notion of payoff in game theory. They employ multi-person game theoretic structure to determine the game played by the employees. They found that the perceived payoff of knowledge sharing can be characterized by a multiperson game and that drivers of individual's behavior are self esteem, expected association, expected contribution, self consistency, level of understanding, time to share, and self interest.

Song et al. [18] analyze the sharing of mutually-complementary knowledge resources across 
organizations in a competitive strategic alliance and examine the conditions of maintaining their cooperation. Their conclusion indicates that, under the Nash balanced condition, the knowledge shring level increases along with the expansion of the sharing cost effect. The optimum knowledge sharing coefficient is in inversely proportional to every alliance member's absorption coefficient on knowledge shared and the investment cost paid by every alliance member on acquiring knowledge. The shared knowledge resource makes every alliance member's expected income increase so that this becomes the source of the power in establishing an alliance.

Yung-Ming Li et al. [8] applies game theory to analyze the incentives of knowledge-sharing activities in various types of communities of practice (COPs), characterized by individual profiles and decision structures. Based on a screening technique, they find that the benefit of knowledge sharing in the incomplete information setting can be the same as that in the complete information setting if the cost of the cost of more efficient community member is smaller than that of less efficient one.

Sharma and Bhattacharya [19] identified four organizational knowledge dilemmas: "silos of knowledge", "tragedy of the knowledge commons", "knowledge friction" and "knowledge toxicity", and attempt to resolve them using game theory. They adopt a game theoretic analysis of these scenarios using the PARTS framework in order to providing a useful understanding of knowledge flows within organizational eco-systems. They indicate that game theoretic reasoning of strategic dilemmas can be instrumental as a guide for the organizations in applying effective strategies and achieving their desired outcome. They also find that game theory should not seek to predict phenomena of interest but give a perspective of the possibilities so that decisions may be so framed.

Jiang et al. [20] build an evolutionary game model to depict knowledge sharing phenomenon in the virtual community. The results show that the evolutionary game rule and social network structure significantly influence the degree of cooperation and knowledge sharing among users. The greater noise the network information has the less stable the users' behavior will be. One can thus identify an optimal initial cooperation rate to facilitate the system to reach equilibrium state quickly.

Though many studies have empirically examined what drives continued knowledge sharing, and fewer studies have explored the issues from the perspective of mathematical modeling and simulation approach in product innovation team. There are some limitations under solved. For example, in Li's study [8], they only considered one dimensional characteristics of knowledge. According to the extent of usefulness of knowledge, the knowledge that each employee might hold can be categorized as either being complementary knowledge or supplementary knowledge. In addition, they also have ignored the problem that an individual's energy is limited. Apart from public work, each person has their private work to do.

The goal of this research is to better understand knowledge-sharing activities by investigating how product innovation team members spend their time and effort on knowledge transfer and share. Knowledge sharing is a complex game process. The formation of knowledge transfer intention depends on the corresponding motivation and guidance. The internal members in $\mathrm{MNC}$ are changeable. And their relationship is a dynamic cooperative competition relationship. In addition, there are different motivation, intention, profit and cost in knowledge transfer. Based on the above reason, game method will be used to analyze the behaviors of internal members' knowledge transfer and its influencing factors. This research will study condition, stability and continuity of knowledge sharing of product innovation team by using game theory. The next section introduces the model of knowledge transfer. Three typical organizational scenarios, made up of a combination of dilemmas, are introduced and resolved using game theory. And Simulation results are shown is Section Three. The paper concludes with the key findings, a set of recommendations and guidelines for the management to promote knowledge sharing and stimulate the employee's knowledge sharing behavior in Section Four.

The knowledge of team members is usually complementary. Every team members who perform the team task grasp knowledge that is conducive to others' progress. The useful knowledge is distributed in the entire team. Each member is not only a contribution, but also a recipient in the process of team knowledge transfer and share. Consider the knowledge sender is willing and able to share knowledge, and the knowledge receiver is willing and able to combine this new knowledge with his or her existing knowledge and use it. In addition, the studies consider knowledge as an object that can be directly observed, stored and transferred for use and reuse. Unused or underused knowledge can potentially be applied to create or increase value by contributing to develop new or improved products, services and tools. The value creation of knowledge is depended on the team members' prior knowledge, knowledge absorptive capacity, resources, and interactions with actors in product innovation team.

\section{The Model}

Consider a knowledge aggregation and sharing model for $n$ members in a product innovation team. The team is composed of two types of members: $\eta$ repatriates and $n-\eta$ ordinary staffs, who have no overseas experience. These members want to develop new products through knowledge exchange and transfer. Each member has two types of knowledge: complementary knowledge and supplementary knowledge. In [21], the expected value of a member's knowledge is denoted as either of a high type, $K_{h}$, or a low type, $K_{l}$, where $K_{h}>K_{l}>0$. Since there are two types of knowledge, $K_{c i} \in\left\{K_{c h}, K_{c l}\right\}$ is used to denote the expected value of a member's complementary knowledge, and $K_{s i} \in\left\{K_{s h}, K_{s l}\right\}$ to denote the expected value of a member's supplementary knowledge. Each member decides on $x_{c i}, x_{s i}, x_{p i}$, the quantity of effort he/she exerts on complementary, supplementary 
knowledge and his/her personal work affairs, respectively. Thus, individual complementary knowledge contribution in the team can be assumed to be $K_{c i} x_{c i}$, and supplementary knowledge contribution $K_{s i} x_{s i}$. This notation is adopted because a high-type member makes a more valuable contribution than a low-type one when they give equal efforts. Hence, the amount of complementary and supplementary knowledge aggregation can be defined as $Q_{c}=\sum_{i} K_{c i} x_{c i}$ and $Q_{s}=\sum_{i} K_{s i} x_{s i}$, respectively.

Suppose all members in the product innovation team can access all others' knowledge by direct interaction or by proper media. Then the knowledge sharing benefits a member receives can be defined as $f\left(x_{p i}, Q_{c}, Q_{s}\right)$. For the sake of analytical convenience, it is assumed that the benefit function $f(\cdot)$ can be represented by the Cobb-Douglas utility function $f\left(x_{p i}, Q_{c}, Q_{s}\right)=\alpha \ln x_{p i}+\beta \ln Q_{c}+\gamma \ln Q_{s}$. In addition, $C_{c i} \in\left\{C_{c h}, C_{c l}\right\}, C_{s i} \in\left\{C_{s h}, C_{s l}\right\}$, and $C_{p i}$ are defined as the cost of a member's complementary, supplementary knowledge, and personal affairs, respectively. Each member receives a reward $\mathrm{M}_{i}$ for his/her efforts. Suppose all members are rational and self-interested in order to maximize the benefit under a given reward. Next, three types of setting will be discussed to analyze the performance of knowledge sharing: knowledge sharing with individual decision making (form 1), knowledge sharing with overall coordination (form 2), and knowledge sharing with incentive mechanism (form 3 ).

\subsection{Individual Decision Making}

When exerting effort without overall coordination, each member would choose $x_{c i}, x_{s i}, x_{p i}$ to maximize individual benefit function: $\max f\left(x_{p i}, Q_{c}, Q_{s}\right)$, subject to $C_{c i} x_{c i}+$ $C_{s i} x_{s i}+C_{p i} x_{p i} \leq M_{i}$. Solving the model simultaneously for each member yields Nash equilibrium.

Proposition 1

1. The member with lower knowledge-cost ratios always free ride on others with the higher knowledge- cost ratio. Formally, $x_{c i}^{*}=\frac{\beta}{m_{c} \lambda_{i} C_{c i}}$ if $\frac{K_{c i}}{\lambda_{i} C_{c i}}=R_{\max c}$, otherwise $x_{c i}^{*}=0$; $x_{s i}^{*}=\frac{\gamma}{m_{s} \lambda_{i} c_{s i}}$ if $\frac{K_{s i}}{\lambda_{i} c_{s i}}=R_{\max s}$, otherwise $x_{s i}^{*}=0 . R_{\max c}$, $R_{\max s}, m_{c}, m_{s}$ are defined in the proof.

2 . For any team size, the amount of complementary and supplementary knowledge aggregation is fixed. Formally, $Q_{c}^{*}=\beta R_{\max c}, Q_{s}^{*}=\gamma R_{\max s}$.

Proof: Solving $\max f\left(x_{p i}, Q_{c}, Q_{s}\right)+\lambda_{i}\left(M_{i}-C_{c i} x_{c i}-\right.$ $\left.C_{s i} x_{s i}-C_{p i} x_{p i}\right)\left(\lambda_{i}\right.$ is Lagrange multiplier) yields $\frac{\partial f}{\partial x_{p i}}=$ $\lambda_{i} C_{p i}, \frac{\partial f}{\partial Q_{c}} K_{c i}=\lambda_{i} C_{c i}, \frac{\partial f}{\partial Q_{s}} K_{s i}=\lambda_{i} C_{s i}$. Then, $Q_{c}=\frac{\beta K_{c i}}{\lambda_{i} C_{c i}}$, $Q_{s}=\frac{\gamma K_{s i}}{\lambda_{i} C_{s i}}, \quad x_{p i}=\frac{\alpha}{\lambda_{i} c_{p i}}$. So $x_{c i}=\frac{\beta}{\lambda_{i} C_{c i}}-\frac{1}{K_{c i}} \sum_{j \neq i} K_{c j} x_{c j}$, $x_{s i}=\frac{\gamma}{\lambda_{i} C_{s i}}-\frac{1}{K_{s i}} \sum_{j \neq i} K_{s j} x_{s j}$. Thus, when $\frac{K_{c h}}{\lambda_{i} C_{c h}} \neq \frac{K_{c l}}{\lambda_{j} C_{c l}}$ and $\frac{K_{s h}}{\lambda_{i} C_{s h}} \neq \frac{K_{s l}}{\lambda_{j} C_{s l}}$ hold, there is a corner solution, that is each member with the lower knowledge-cost ratios always free ride on others with the higher knowledge-cost ratios. The Nash equilibrium in this case is given by $x_{c i}^{*}=\frac{\beta}{m_{c} \lambda_{i} C_{c i}}$ if $\frac{K_{c i}}{\lambda_{i} C_{c i}}=$
$R_{\max c}$, otherwise $x_{c i}^{*}=0 ; x_{s i}^{*}=\frac{\gamma}{m_{s} \lambda_{i} c_{s i}}$ if $\frac{K_{s i}}{\lambda_{i} C_{s i}}=R_{\max s}$, otherwise $x_{s i}^{*}=0$, where $R_{\max c}=\max \left\{\frac{K_{c i}}{\lambda_{i C_{c i}}}\right\}, R_{\max s}=$ $\max \left\{\frac{K_{s i}}{\lambda_{i C_{s i}}}\right\}, m_{c}$ and $m_{s}$ denote the number of members with the higher complementary, supplementary knowledge, respectively. $\lambda_{i}=\left(\alpha+\frac{\beta I_{c}(i)}{m_{c}}+\frac{\gamma I_{s}(i)}{m_{s}}\right) / M_{i}$, where $I_{c}(i)=1$ if member $i$ has higher complementary knowledge-cost ratios, otherwise $I_{c}(i)=0 ; I_{S}(i)=1$ if member $i$ has higher complementary knowledge-cost ratios, otherwise $I_{s}(i)=0$.

\subsection{Overall Coordination}

Next, the performance of knowledge sharing in form 2 will be analyzed, where each member's action is directed by overall coordination. Under overall coordination, it will be proved that the performance of knowledge sharing is efficient. The knowledge-sharing problem under overall coordination can be formulated as $\max \sum_{i=1}^{n} f\left(x_{p i}, Q_{c}, Q_{s}\right)$ subject to $C_{c i} x_{c i}+C_{s i} x_{s i}+C_{p i} x_{p i} \leq M_{i} \quad(i=1,2, \ldots, n)$. Solving the model gives the following results.

Proposition 2

1. The activity of knowledge sharing would be supported by the members with the higher knowledge-cost ratios. Formally, $x_{c i}^{*}=\frac{n \beta}{m_{c} \lambda_{i} C_{c i}}$ if $\frac{K_{c i}}{\lambda_{i} C_{c i}}=R_{\max c}$, otherwise $x_{c i}^{*}=0 ; x_{s i}^{*}=$ $\frac{n \gamma}{m_{s} \lambda_{i} C_{s i}}$ if $\frac{K_{s i}}{\lambda_{i} C_{s i}}=R_{\max s}$, otherwise $x_{s i}^{*}=0$.

2 . The amount of complementary and supplementary knowledge aggregation increases with the team size. Formally, $Q_{c}^{*}=n \beta R_{\max c}, Q_{s}^{*}=n \gamma R_{\max s}$.

Proof: $\quad$ Solving $\max \sum_{i=1}^{n} f\left(x_{p i}, Q_{c}, Q_{s}\right)+\lambda_{i}\left(M_{i}-\right.$ $\left.C_{c i} x_{c i}-C_{s i} x_{s i}-C_{p i} x_{p i}\right)$ ( $\lambda_{i}$ is Lagrange multiplier) yields $\frac{\partial f}{\partial x_{p i}}=\lambda_{i} C_{p i}, \quad \sum_{i=1}^{n} \frac{\partial f}{\partial Q_{c}} K_{c i}=\lambda_{i} C_{c i}, \quad \sum_{i=1}^{n} \frac{\partial f}{\partial Q_{s}} K_{s i}=\lambda_{i} C_{s i}$. Then, $Q_{c}=\frac{n \beta K_{c i}}{\lambda_{i} C_{c i}}, Q_{s}=\frac{n \gamma K_{s i}}{\lambda_{i} C_{s i}}, \quad x_{p i}=\frac{\alpha}{\lambda_{i} C_{p i}}$. Therefore, when $\frac{K_{c h}}{\lambda_{i} C_{c h}} \neq \frac{K_{c l}}{\lambda_{j} C_{c l}}$ and $\frac{K_{s h}}{\lambda_{i} C_{s h}} \neq \frac{K_{s l}}{\lambda_{j} C_{s l}}$ hold, each member effort is given by $x_{c i}^{*}=\frac{n \beta}{m_{c} \lambda_{i} C_{c i}}$ if $\frac{K_{c i}}{\lambda_{i} C_{c i}}=R_{\max c}$, otherwise $x_{c i}^{*}=0$; $x_{s i}^{*}=\frac{n \gamma}{m_{s} \lambda_{i} C_{s i}}$ if $\frac{K_{s i}}{\lambda_{i} c_{s i}}=R_{\max s}$, otherwise $x_{s i}^{*}=0$, where $\lambda_{i}=\left(\alpha+\frac{n \beta I_{C}(i)}{m_{c}}+\frac{n \gamma I_{s}(i)}{m_{s}}\right) / M_{i}$

\subsection{Incentive Mechanism}

Finally, an incentive mechanism is designed to induce efficient individual knowledge sharing without overall coordination. Under the incentive mechanism, each member would choose $x_{c i}, x_{s i}, x_{p i}$ to maximize individual benefit. Formally, the problem is formally expressed by $\max f\left(x_{p i}, Q_{c}, Q_{s}\right)$ subject to $C_{c i} x_{c i}+C_{s i} x_{s i}+C_{p i} x_{p i} \leq$ $M_{i}+P_{c i} x_{c i}+P_{s i} x_{s i}$, where $P_{c i} x_{c i}, P_{s i} x_{s i}$ is compensation for member $i$.

\section{Proposition 3}

In form 3 , if all members are paid $P_{c i} x_{c i}, P_{s i} x_{s i}$ based on their types, the benefit of knowledge sharing in form 1 is the same as that in form 2. Formally, $P_{c i}=\frac{(n-1) C_{c i}}{n}$ if $\frac{K_{c i}}{\lambda_{i} C_{c i}}=$ 
$R_{\max c}$, otherwise $P_{c i}=0 ; P_{s i}=\frac{(n-1) C_{s i}}{n}$ if $\frac{K_{s i}}{\lambda_{i} C_{s i}}=R_{\max s}$, otherwise $P_{s i}=0$.

Proof: Solving $\max f\left(x_{p i}, Q_{c}, Q_{s}\right)+\lambda_{i}\left(M_{i}+P_{c i} x_{c i}+\right.$ $\left.P_{s i} x_{s i}-C_{c i} x_{c i}-C_{s i} x_{s i}-C_{p i} x_{p i}\right)\left(\lambda_{i}\right.$ is Lagrange multiplier $)$ yields $\frac{\partial f}{\partial x_{p i}}=\lambda_{i} C_{p i}, \frac{\partial f}{\partial Q_{c}} K_{c i}=\lambda_{i}\left(C_{c i}-P_{c i}\right), \frac{\partial f}{\partial Q_{s}} K_{s i}=$ $\lambda_{i}\left(C_{s i}-P_{s i}\right)$. Then, $Q_{c}=\frac{\beta K_{c i}}{\lambda_{i}\left(C_{c i}-P_{c i}\right)}, Q_{s}=\frac{\gamma K_{s i}}{\lambda_{i}\left(C_{s i}-P_{s i}\right)}$, $x_{p i}=\frac{\alpha}{\lambda_{i} C_{p i}}$. Thus, comparing $Q_{c}$ here with $Q_{c}$ in the proof of proposition 2, that is $\frac{\beta K_{c i}}{\lambda_{i}\left(C_{c i}-P_{c i}\right)}=\frac{n \beta K_{c i}}{\lambda_{i} C_{c i}}, P_{c i}=\frac{(n-1) C_{c i}}{n}$. Only the members with higher knowledge-cost ratio would make contribution to knowledge aggregation. Therefore, only they receive compensation. Formally, $P_{c i}=\frac{(n-1) C_{c i}}{n}$ if $\frac{K_{c i}}{\lambda_{i} C_{c i}}=R_{\max c}$, otherwise $P_{c i}=0$; Similarly, $P_{s i}=\frac{(n-1) C_{s i}}{n}$ if $\frac{K_{s i}}{\lambda_{i} C_{s i}}=R_{\max s}$, otherwise $P_{s i}=0$.

\section{Simulations}

In this section, a simulation example is presented to verify the theoretical analysis. In the simulation, the parameters are set as follows: $n=30, \eta=10, \alpha=0.1, \beta=0.2, \gamma=$ $0.2, K_{c h}=6, K_{c l}=2, K_{s h}=6, K_{s l}=2, C_{c h}=2, C_{c l}=1$,

$C_{s h}=2, C_{s l}=1, M_{i}=8$. Assume the repatriates have higher complementary knowledge than ordinary staffs, and ordinary staffs have higher supplementary knowledge than repatriates.

In this scenario, the simulation results are shown in Table. 1 (The variables with subscript $r$ and $o$ denote variables related to repatriates and ordinary staffs, respectively). From the table, it shows that $Q_{c}$ and $Q_{s}$ in form 1 are less than these in form 2. It shows that individual decision-making results in under provision of knowledge aggregation. $Q_{c}$ and $Q_{s}$ in form 3 are equal to these in form 2 . The compensations for member are $P_{c r}=1.93, P_{c o}=0, P_{s r}=0, P_{s o}=1.93$. It shows that individual decision making with incentive mechanism is as efficient as overall coordination. In addition, $x_{s r}=0, x_{c o}=0$. Only repatriates exert efforts to complementary knowledge aggregation and only ordinary staffs exert effort to supplementary knowledge aggregation. It seems free rider problem, but in fact it would make best use of human resource and let proper people do proper things.

Table 1. Simulation results.

\begin{tabular}{lllllllll}
\hline From & $\boldsymbol{Q}_{\boldsymbol{c}}$ & $\boldsymbol{Q}_{\boldsymbol{s}}$ & $\boldsymbol{x}_{\boldsymbol{c r}}$ & $\boldsymbol{x}_{\boldsymbol{s} \boldsymbol{r}}$ & $\boldsymbol{x}_{\boldsymbol{p r}}$ & $\boldsymbol{x}_{\boldsymbol{c o}}$ & $\boldsymbol{x}_{\boldsymbol{s o}}$ & $\boldsymbol{x}_{\boldsymbol{p o}}$ \\
\hline 1 & 40 & 43.6 & 0.67 & 0 & 6.67 & 0 & 0.36 & 7.27 \\
2 & 205.7 & 360 & 3.43 & 0 & 1.14 & 0 & 3 & 2 \\
3 & 205.7 & 360 & 3.43 & 0 & 7.77 & 0 & 3 & 7.8 \\
\hline
\end{tabular}

In the following, the sensibility of the parameters $\eta, M_{i}, \beta, n$ will be analyzed. Let $\eta$ vary from 1 to 29 ; the curves of $Q_{c}$ and $Q_{s}$ can be obtained (Figure 1 and Figure 2). Figure 1 shows complementary knowledge aggregation increase with the number of repatriates. Figure 2 shows supplementary knowledge aggregation decrease with the number of repatriates. This shows that the proportion of members influence the knowledge aggravation.

Let $M_{i}$ vary from 2 to 10 ; the curves of $Q_{c}$ and $Q_{s}$ are shown in Figure 3 and Figure 4, respectively. Figure 3 and Figure 4 show that complementary and supplementary knowledge aggregations increase with rewards paid by enterprises.

Let $\beta$ vary from 0.1 to 0.6 ; the curve of $Q_{c}$ is shown in Figure 5. Let $\gamma$ vary from 0.1 to 0.6 , the curve of $Q_{s}$ can be seen in Figure 6. Figure 5 and Figure 6 show that complementary and supplementary knowledge aggregations increase with relative importance factors of complementary and supplementary knowledge, respectively.

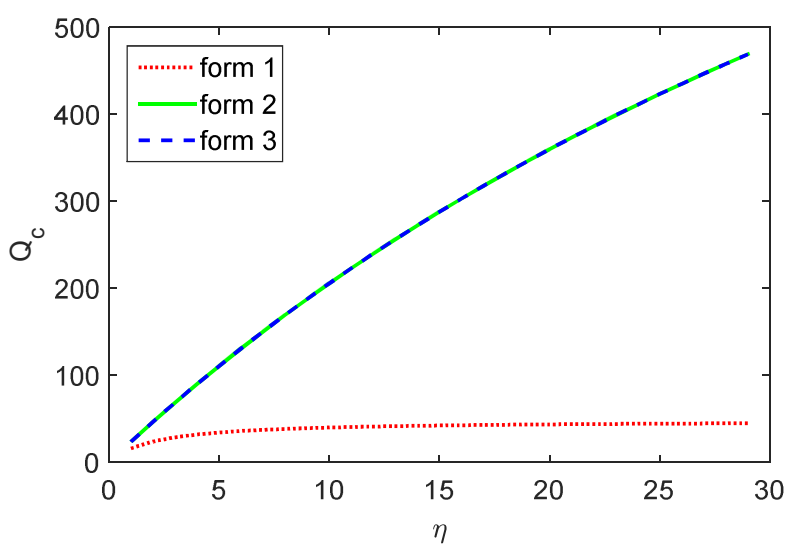

Figure 1. $Q_{c}$ and $\eta$.

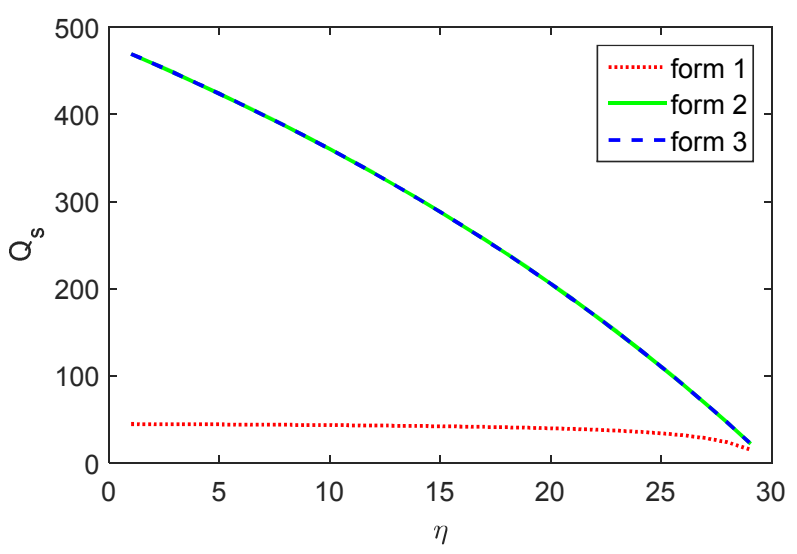

Figure 2. $Q_{s}$ and $\eta$.

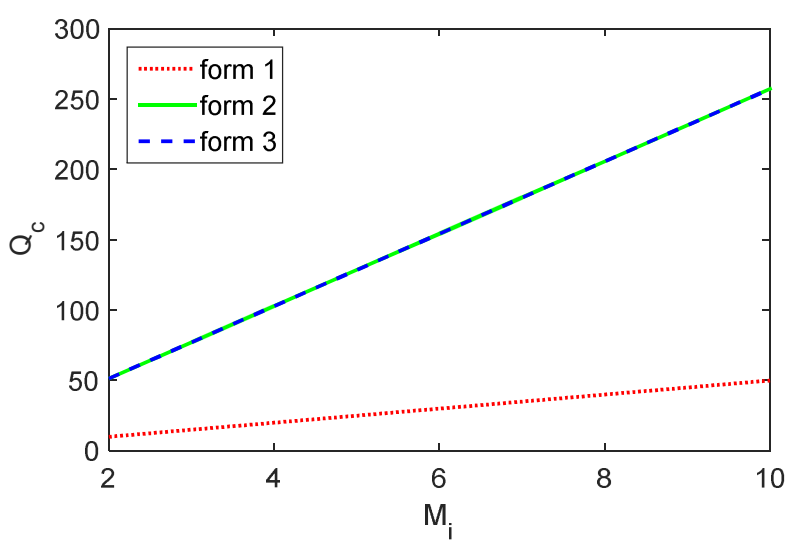

Figure 3. $Q_{c}$ and $M_{i}$. 


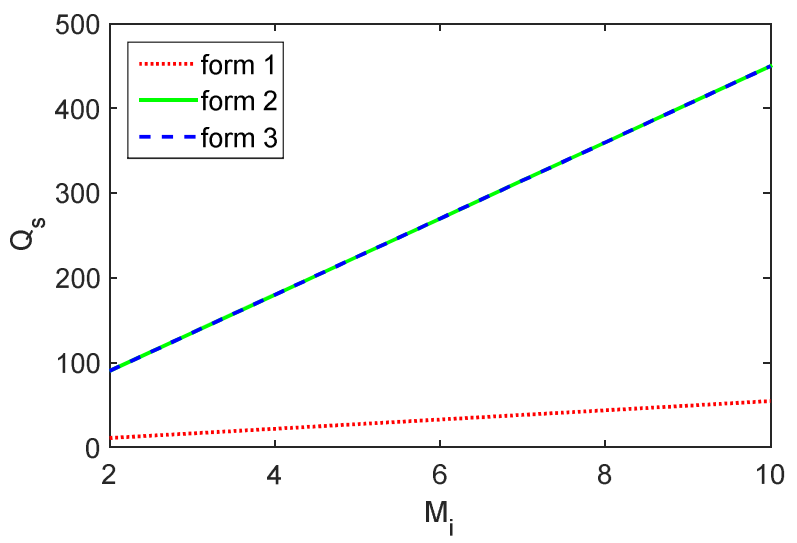

Figure 4. $Q_{s}$ and $M_{i}$.

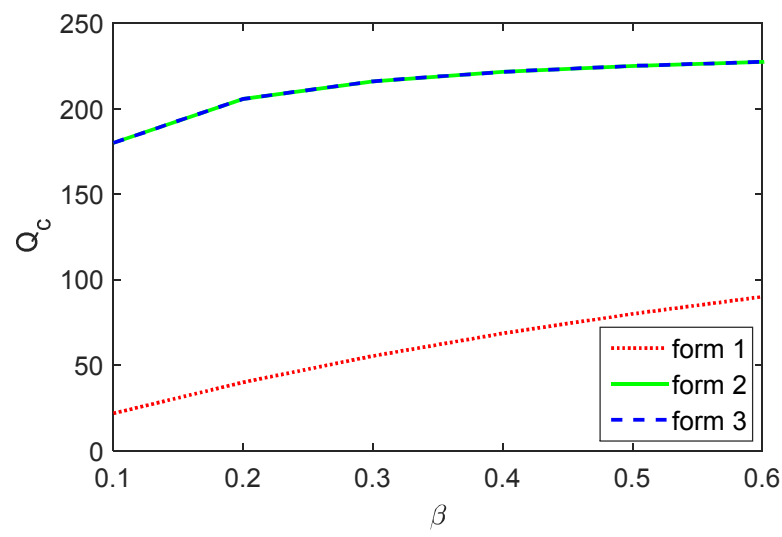

Figure 5. $Q_{c}$ and $\beta$.

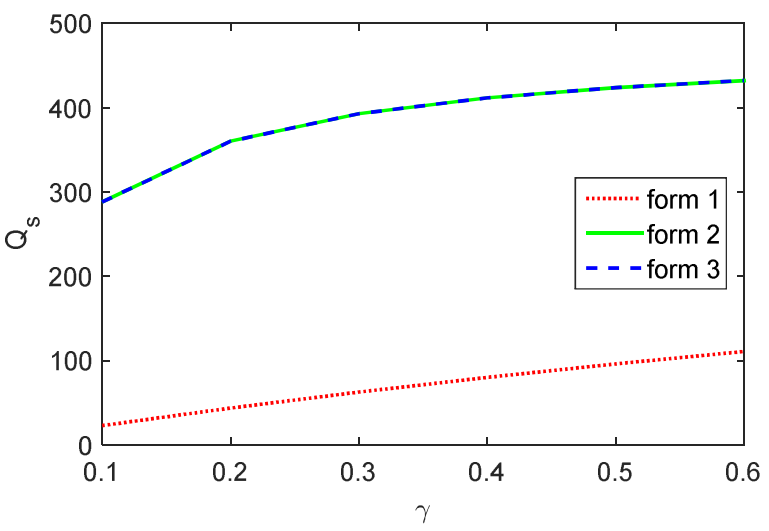

Figure 6. $Q_{s}$ and $\gamma$.

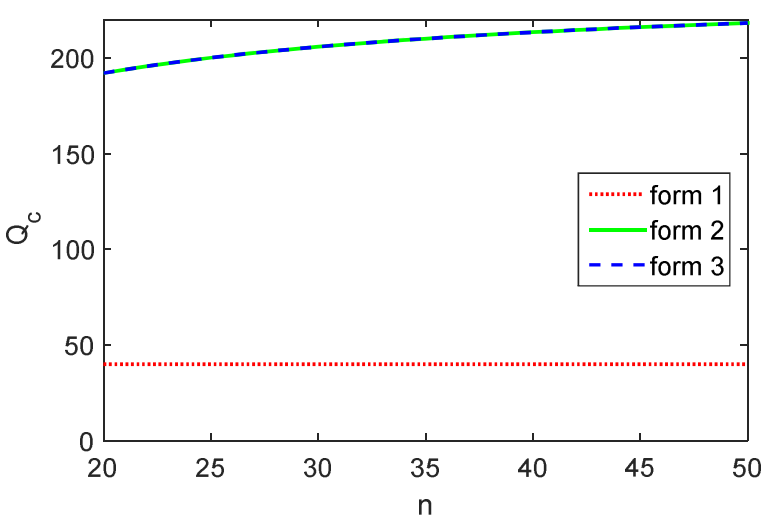

Figure 7. $Q_{c}$ and $n$.

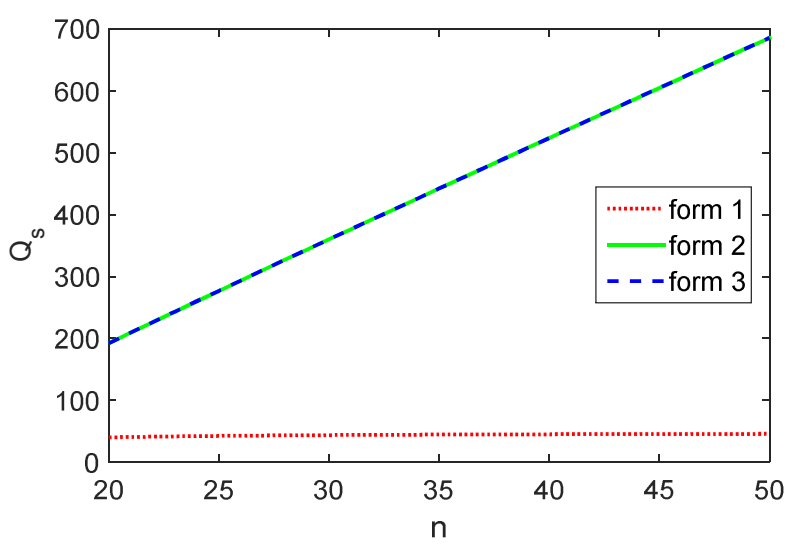

Figure 8. $Q_{s}$ and $n$.

Let $n$ vary from 20 to 50; the curves of $Q_{c}$ and $Q_{s}$ can be obtained (Figure 7 and Figure 8 ). Figure 7 and Figure 8 show the amount of complementary and supplementary knowledge aggregation is fixed for any team size. The amount of complementary and supplementary knowledge aggregation with overall coordination and individual decision making with incentive mechanism increases with the team size, respectively.

\section{Conclusions}

This research helps in understanding why team members choose to or not to engage in a knowledge sharing activity. Knowing the game can help put an effective strategy to promote the knowledge sharing behavior in product innovation team.

The improving work is done based on the literature [8]. This new approach is applied in the knowledge sharing and aggravation of product innovation team. In this research, the specific improvement is mainly reflected in the following aspects: (1) The individual's energy is limited, so a constrain condition is added to the personal energy.; (2) In the actual product development process, the knowledge is not homogeneous. According to the different roles in the process of product innovation [5], knowledge is divided into complementary knowledge and supplementary knowledge; (3) In order to in line with the reality, a variable is added, which is related to work, but not related to knowledge aggravation. In fact, in real life each team member has limited energy and has some private work to do. It is assumed that all team members are rational economic and self-interest. Therefore, this improvement can make the mathematical model more in line with the actual situation and characteristics of knowledge sharing in product innovation team, which can obtain a more accurate conclusion and put forward a series of countermeasures and suggestions.

New results are obtained on the basis of the above improvements: (1) Literature [8] points out that the amount of knowledge aggregation is not related to the size of the team in individual cases. The results also support the conclusion of this study. However, literature [8] believes that the amount of knowledge aggregation is not related to the proportion of 
members with knowledge. It is found that when the size of team is fixed, the amount of knowledge aggregation has positive relationship with the proportion of members with knowledge. Therefore, according to the strategic objectives of the team, the relative importance coefficient of knowledge can be adjusted, which can aggregate more required knowledge. The results are different from the literature [8]. (2) The constraint conditions are relaxed and compensation is increased, the amount of aggregation of these two kinds of knowledge will become more.

According to these new founding, in order to improve continuity and stability of knowledge sharing in product innovation team, recommendations for mangers are as follows: Building a culture of knowledge sharing, cooperation and exchange; increasing their sense of belonging; providing a perfect career development plan for team members and giving higher occupational commitment and organizational commitment; strengthening the protection of intellectual property rights and reducing the loss of the members' knowledge spillover; improving the enthusiasm of members' knowledge transfer; controlling team size moderately and improving team stability in order to maintaining long-term cooperative relationship.

One of future research issues is how to efficiently improve the credibility of knowledge in open architectures based on the spirit of Web 2.0. However, it also generates many new questions and challenges. On the other hand, because knowledge can be treated as a good and people can trade their own knowledge in a market, one of future directions is to conduct an economic analysis on knowledge trading platform, such as Cramster. com. therefore, many interesting issues are worthy of further study such as how to price the membership fee, how to establish a reputation system to keep the quality of knowledge provided by members, and how to determine the DRM level of online knowledge.

\section{References}

[1] Tamer Cavusgil S, Calantone R J, Zhao Y. Tacit knowledge transfer and firm innovation capability [J]. Journal of business \& industrial marketing, 2003, 18(1): 6-21.

[2] Sarin S, McDermott C. The effect of team leader characteristics on learning, knowledge application, and performance of cross-functional new product development teams [J]. Decision sciences, 2003, 34(4): 707-739.

[3] Liao Y, Barnes J. Knowledge acquisition and product innovation flexibility in SMEs [J]. Business Process Management Journal, 2015, 21(6): 1257-1278.

[4] $\mathrm{Xu} \mathrm{S}$. Balancing the Two Knowledge Dimensions in Innovation Efforts: An Empirical Examination among Pharmaceutical Firms [J]. Journal of Product Innovation Management, 2015, 32(4): 610-621.

[5] Knudsen M P. The relative importance of interfirm relationships and knowledge transfer for new product development success [J]. Journal of Product Innovation Management, 2007, 24(2): 117-138.
[6] Hargadon A, Sutton R I. Technology brokering and innovation in a product development firm [J]. Administrative science quarterly, 1997: 716-749.

[7] Choi H S, Thompson L. Old wine in a new bottle: Impact of membership change on group creativity [J]. Organizational Behavior and human decision processes, 2005, 98(2): 121-132.

[8] Li Y M, Jhang-Li J H. Knowledge sharing in communities of practice: A game theoretic analysis [J]. European Journal of Operational Research, 2010, 207(2): 1052-1064.

[9] Dyer J H, Nobeoka K. Creating and managing a high-performance knowledge-sharing network: the Toyota case [J]. Strategic management journal, 2000, 21(3): 345-367.

[10] $\mathrm{Ba} \mathrm{S}$, Stallaert J, Whinston A B. Research commentary: introducing a third dimension in information systems design - the case for incentive alignment [J]. Information systems research, 2001, 12(3): 225-239.

[11] $\mathrm{Ba} \mathrm{S}$, Stallaert J, Whinston A. Optimal Investment in Knowledge Within a Firm Using a Market Mechanism [J]. Management Science, 2001, 47(9): 1203-1219.

[12] Bartol K M, Srivastava A. Encouraging knowledge sharing: The role of organizational reward systems [J]. Journal of Leadership \& Organizational Studies, 2002, 9(1): 64-76.

[13] Ho S P, Wu P C, Hsu Y. Knowledge sharing model and its implication on knowledge categorization and management $[\mathrm{C}] / /$ Proceedings of the 23rd International Symposium on Automation and Robotics in Construction (ISARC). 2006: 751-756.

[14] Ardichvili A, Page V, Wentling T. Motivation and barriers to participation in virtual knowledge-sharing communities of practice [J]. Journal of knowledge management, 2003, 7(1): 64-77.

[15] Shih M H, Tsai H T, Wu C C, et al. A holistic knowledge sharing framework in high-tech firms: game and co-opetition perspectives [J]. International Journal of Technology Management, 2006, 36(4): 354-367.

[16] Bandyopadhyay S, Pathak P. Knowledge sharing and cooperation in outsourcing projects - A game theoretic analysis [J]. Decision Support Systems, 2007, 43(2): 349-358.

[17] Samieh H M, Wahba K. Knowledge sharing behavior from game theory and socio-psychology perspectives [C]//System Sciences, 2007. HICSS 2007. 40th Annual Hawaii International Conference on. IEEE, 2007: 187c-187c.

[18] Song $\mathrm{X}, \mathrm{Li} \mathrm{J}, \mathrm{Xu} \mathrm{N}$. Dynamic game analysis on knowledge-sharing and knowledge-spillover in competitive alliances [C]. In: Proceedings of the 2008 International Conference on Computer Science and Software Engineering, 2008: 783-786.

[19] Sharma R, Bhattacharya S. Knowledge dilemmas within organizations: Resolutions from game theory [J]. Knowledge Based Systems, 2013, 45(7): 100-113.

[20] Jiang G, Ma F, Shang J. Evolution of knowledge sharing behavior in social commerce: An agent-based computational approach [J]. Information Sciences, 2014, 278(10): 250-266.

[21] Lin L, Geng X, Whinston A B. A sender-receiver framework for knowledge transfer [J]. Mis quarterly, 2005, 29(2): 197-219. 